\title{
Blood pressure management and progression of chronic kidney disease in a canine remnant kidney model
}

\author{
Jun Gu Kang ${ }^{1, \star}$, Mi-yeon $\mathrm{Yu}^{2, \star}$, Hajeong Lee ${ }^{2}$, Dong Ki Kim ${ }^{1,2}$, Kwon Wook Joo ${ }^{1,2}$, Yon Su Kim ${ }^{1,2}$ \\ and Seung Hee Yang ${ }^{1}$ \\ ${ }^{1}$ Kidney Research Institute, Seoul National University, Seoul, Korea \\ ${ }^{2}$ Department of Internal Medicine, Seoul National University Hospital, Seoul, Korea
}

\begin{abstract}
The canine remnant kidney model is fundamental to understanding the relationship between hypertension and chronic kidney disease (CKD). This study aimed to create a 1/16 remnant kidney model and to determine whether blood pressure (BP) control affects the progression of $\mathrm{CKD}$. A group of dogs received BP treatment (group A) and another received BP treatment except for the first 2 weeks (group B). The remnant kidney model was induced using a two-step subtotal nephrectomy method; dogs received antihypertensive therapy. Systolic BP, blood urea nitrogen, serum creatinine, urinary protein, and creatinine levels were measured weekly. Kidney tissues were obtained at the conclusion of the study. Systolic BP was controlled to $<160 \mathrm{mmHg}$ in both groups for 18 weeks, except for the first 2 weeks in group B. Proteinuria was elevated after renal ligation in both groups, but gradually increased in group B and decreased in group A $(p=0.009)$. Blood urea nitrogen $(p=0.014)$ and creatinine $(p=0.020)$ levels were higher in group B than in group A. More histological damage was observed in group B than in group A. Induction of $1 / 16$ nephrectomy successfully established CKD. Control of BP may be important to prevent or control the progression of CKD in dogs.
\end{abstract}

Key words: Chronic kidney disease - Dog - Hypertension - Nephrectomy

\section{Introduction}

The remnant kidney model is created by unilateral nephrectomy $(\mathrm{Nx})$ and partial infarction/amputation of the remaining kidney, and has made critical contributions to the understanding of chronic kidney disease (CKD) and hypertension (Purkerson et al. 1976; Hostetter et al. 1981; Griffin et al. 1994; Ibrahim and Hostetter 1998). Although models of progressive nephropathy have been well established in rats and mice, it is unclear how to demonstrate progression of renal failure in other species (Kren and Hostetter 1990; Griffin et al. 1994; Al Banchaabouchi et al. 1998; Ibrahim and Hostetter 1998; Kujal and Vernerova 2008; Gava et al. 2012).

Correspondence to: Seung Hee Yang, Kidney Research Institute, Seoul National University, 101 Daehakro Jongno-gu, Seoul 110744, Republic of Korea

E-mail: ysh5794@gmail.com

*These authors contributed equally to this work.
The canine remnant kidney model, with $3 / 4 \mathrm{Nx}$, was initially developed to study the relationship between a high level of dietary protein and renal function in dogs (Bovee et al. 1979). However, there was no evidence of a progressive reduction of renal function in nephrectomized dogs that were fed high dietary protein (Bovee et al. 1979; Robertson et al. 1986). To reduce the renal mass to more than $3 / 4 \mathrm{Nx}, 7 / 8 \mathrm{Nx}$ was used to determine changes in renal function in dogs and rodents after reduction of renal mass (Bourgoignie et al. 1987). Consequently, a canine remnant kidney model with $11 / 12 \mathrm{Nx}$ was reported to enable determination of the influence of dietary protein intake in dogs (Polzin et al. 1988). An even more sophisticated canine remnant kidney model, with $15 / 16 \mathrm{Nx}$, using the ligation of renal arteries and unilateral Nx was then attempted (Brown et al. 1991). However, other techniques have been used to create a canine $\mathrm{CKD}$ model. One report described a combination of the Page model and the remnant kidney model using wrapping on the surface of a resected kidney (Finco 2004). Another technique has involved the use of an ameroid ring constrictor to reduce blood flow in the main renal artery (Dong et al. 2013). 
The canine remnant kidney model has been used to evaluate the clinical outcome and effect of treatment of CKD in dogs (Bovee et al. 1979; Robertson et al. 1986; Bourgoignie et al. 1987; Polzin et al. 1988; Brown et al. 1991). Moreover, this model has recently been used to understand the relationship between renal failure and hypertension (Jacob et al. 2003; Finco 2004; Dong et al. 2013). Induction of CKD causes hypertension (Coulter and Keith 1984), and the control of blood pressure (BP) delays the progression of CKD in animals and humans (Madias 1983; Peterson et al. 1995; Sarnak et al. 2005; Ravera et al. 2006; Upadhyay et al. 2011). A previous study reported an association between mortality risk and systolic BP (SBP) in CKD (Finco 2004). In that study, it was found that the higher $\mathrm{BP}$ group in the canine remnant kidney model exhibited worse renal function than the lower BP group. The importance of strict BP control in early CKD remains an ongoing concern.

The remnant kidney model may be helpful in accelerating the discovery of biomarkers and medical appliances for $\mathrm{CKD}$, as well as the design and testing of novel therapeutic strategies. However, previous studies have included limited serological data or a short experimental period. Therefore, creation of a canine remnant kidney model is important for a better understanding of the long-term effects of fibrosis and medical appliances. Our research interest involves the investigation of renal function and pathological changes in the kidney to determine whether initial BP control in CKD can slow the progression of the disease. The goal of the present study, therefore, was to establish a stable CKD model for application of medical appliances and agents, and to determine whether early BP control affects the progression of CKD.

\section{Materials and Methods}

\section{Experimental dogs}

Twenty-five adult male Beagle dogs (age 14-16 months; weight $8-11 \mathrm{~kg}$ ) were purchased from a commercial supplier (Orient Bio Inc., Korea). The dogs were acclimatized for 7 days before the surgical procedure and were housed in individual cages (width $895 \mathrm{~mm} \times$ length $795 \mathrm{~mm} \times$ height

\begin{tabular}{|c|c|c|}
\hline \multicolumn{2}{|c|}{18 weeks } & Group A (10 CKD) \\
\hline 2 weeks & 16 weeks & Group B (8 CKD) \\
\hline
\end{tabular}

Figure 1. Blood pressure management according to group. Group A was treated the high blood pressure during study period (18 weeks). Group B was also managed the blood pressure during study period, but except for the first 2 weeks.
$765 \mathrm{~mm})$. Temperature $\left(23 \pm 3^{\circ} \mathrm{C}\right)$, humidity $(55 \pm 15 \%)$, and 12-h light-dark intervals were controlled, and the dogs had ad libitum access to water. During the experimental period, the animals were fed a commercially available dry diet containing $25 \%$ protein, $1.2 \%$ phosphorus, and $1 \%$ calcium (Cargill Agri Purina, Korea). The dogs received humane care according to the guidelines of the National Research Council for Care of Laboratory Animals. The study was approved by the Committee of Clinical Research Institute at Seoul National University Hospital.

After the surgical procedure, the dogs were divided into two groups according to whether they received BP treatment during the first 2 weeks of the study. Dogs in group A received an antihypertensive drug during the full study period (18 weeks) if an abnormal state, such as marked hypertension (SBP $>180 \mathrm{mmHg}$ ) (Grauer 2017), anorexia, decreased vitality, or vomiting, was noted. Dogs in group B were not treated for the first 2 weeks but were treated for 16 weeks thereafter (Fig. 1). The antihypertensive agent used was amlodipine (Pfizer, New York, NY, USA) $0.5 \mathrm{mg} / \mathrm{kg}$ orally (Acierno and Labato 2004). After the final measurements, the dogs were euthanized using sodium pentobarbital (100 mg/kg intravenously).

Four sham-operated dogs, in which CKD was not induced, were prepared. Their BP control was adjusted according to the same conditions as dogs in Group A $(n=2)$ and $\mathrm{B}(n=2)$.

\section{Surgical procedures}

After premedication with subcutaneous injections of acepromazine (Boehringer Ingelheim, St. Joseph, MO, USA) $0.1 \mathrm{mg} / \mathrm{kg}$ and atropine sulfate (Je Il Pharmaceutical, Daegu, Korea) $0.05 \mathrm{mg} / \mathrm{kg}$, anesthesia was induced by intravenous injection of tiletamine hydrochloride and zolazepam hydrochloride (Zoletil ${ }^{\oplus}$, Virbac, Carros, France) $5 \mathrm{mg} / \mathrm{kg}$. Anesthesia was maintained using isoflurane 2\%. Eighteen dogs allocated to the CKD group underwent a two-step subtotal Nx (Brown et al. 1991). During the first step, the left kidney was exposed by an incision in the flank. In total, eight branches of the left renal arteries were isolated. For 10\%-15\% infarction of the left kidney, seven of eight left renal arteries were ligated (established by visual identification of topical cyanosis) (Fig. 2). The incised area was closed in layers. One week later, the second step of the procedure was performed. In the CKD group, the dogs were anesthetized (as described above) and a contralateral $\mathrm{Nx}$ of the right kidney was performed. A 1/16 remnant kidney was created by selectively ligating branches of the renal artery. Four dogs allocated to sham surgery underwent the same anesthetic and surgical procedures as the CKD dogs, except that the kidneys were simply manipulated in lieu of renal artery ligation or Nx. After each surgical procedure, tramadol $5 \mathrm{mg} / \mathrm{kg}$ (Tridol, Yuhan, Korea) was administered intravenously, cephalexin 
(Hankook Korus Pharm, Seoul, Korea) $30 \mathrm{mg} / \mathrm{kg}$ orally, and cephradine (Hankook Korus Pharm, Seoul, Korea) 30 mg/ $\mathrm{kg}$ intramuscularly twice per day for 3 days.

\section{Analysis of renal function and hemodynamics}

Blood and spot urine samples were collected from all dogs before the first ( -1 week) and second ( 0 week) surgeries, and weekly thereafter to evaluate blood urea nitrogen (BUN), serum creatinine $(\mathrm{sCr})$, urine protein, and urine creatinine levels using a hematology analyzer (Advia 2012, Siemens, Princeton, NJ, USA) and a biochemical analyzer (Clinical Analyzer 7020, Hitachi, Tokyo, Japan). The urine protein to creatinine ratio $(\mathrm{uP} / \mathrm{C})$ was calculated from a single random urine sample (Monroe et al. 1989; Adams et al. 1992). SBP was measured using a cuff plethysmography device (petMAP, Ramsey Medical Inc., Tampa, FL, USA), with the dog in a relaxed, standing position (i.e., with relaxed corners of the mouth, tail down, and head high).

\section{Histological examination and immunohistochemistry}

All tissue samples were collected after the dogs were euthanized. The left kidneys were excised, rinsed in saline, and fixed in $10 \%$ buffered formaldehyde. Tissue samples were processed for microscopic examination. The sections were cut to $4 \mu \mathrm{m}$ thickness and stained with periodic acid-Schiff (Sigma-Aldrich, St. Louis, MO, USA), Sirius red (Sigma-Aldrich), and Masson's trichrome reagents. Histological changes were verified semi-quantitatively. Masson's trichrome-stained paraffin sections were used to quantify glomerular sclerosis. The glomerulosclerosis index (Haas et al. 2003) was scored as follows: $0=$ normal glomerulus; $1=$ sclerosis involving up to $25 \%$ of the glomerulus; $2=$ sclerosis $>25 \%-50 \%$; $3=$ sclerosis $>50 \%-75 \%$ and/or segmental extracapillary fibrosis or proliferation; and $4=$ global sclerosis $>75 \%$, global extracapillary fibrosis, or complete collapse of the glomerular tuft.

Glomerular injury was assessed by a renal pathologist in a blinded fashion. A minimum of 50 glomeruli per canine kidney were evaluated, with the mean was used as a representative value for the dog.

Endogenous streptavidin activity was blocked using $0.3 \%$ hydrogen peroxide. Antigens were retrieved by heating paraffin-embedded sections in $10 \%$ citrate buffer in a microwave oven on 5 occasions for $5 \mathrm{~min}$ each. The stained slides were photographed using an inverted microscope (Olympus Corporation of the Americas, Center Valley, PA, USA). Paraffin sections of each kidney were obtained $24 \mathrm{~h}$ after administration of sulfatide (20 $\mu \mathrm{g}$ per dog, intravenously). For the immunofluorescence study, the paraffin-embedded kidney was cut into $4 \mu \mathrm{m}$ slices. The kidney sections were deparaffinized and rehydrated with ethanol and xylene.
Markers of fibrosis were estimated using collagen type IV and aSMA assays (Abcam, Cambridge, MA, USA) according to manufacturer's instructions. Macrophage counts were estimated using a CD68 antibody (Abcam), and expressed as a percentage of total nuclei per six fields. These nuclei were visualized using hematoxylin (Sigma-Aldrich). Transcription factors were estimated using NF-kB/p65 and p-ERK antibodies (Abcam).

\section{Statistical analysis}

The results are expressed as mean and standard deviation, or mean and standard error, as indicated. The Student's $t$-test was used for between-group comparisons. When comparing more than two groups, two-way analysis of variance with Tukey's post hoc test was used. Statistical analysis was performed using GraphPad Prism 5.0 (GraphPad Software, San Diego, CA, USA). Statistical significance was set at $p<0.05$.

\section{Results}

\section{Renal arterial pattern of Beagle dogs}

In a previous study, the canine renal arteries were divided into single and double, with no statistically significant difference between the right and left kidneys (Marques-Sampaio et al. 2007). However, that study was limited to the renal arterial pattern of mongrel dogs. In the present study, the left renal arteries of 22 male Beagle dogs were isolated from the adipose tissue in the renal hilum and ligated. All dogs had a single renal artery and two main branches. Furthermore, the types of renal arteries were identical in 21 of the 22 dogs and similar to the type I (a) branching pattern reported in a previous study by Marques-Sampaio et al. (2007). However, the subbranches of the caudal renal artery portion were different from type I (a). In the Beagle dogs, the caudal division of the renal artery was again divided into 2 sub-branches, and each sub-branch was further divided into 2 (middle zone) and 3 (caudal zone) interlobar branches. The interlobar branch was located inside the kidney tissue, except for a small portion of cleaving interlobar branches from the sub-branch. This small portion was used to create the $1 / 16$ remnant kidney model in the Beagle dog. The ischemic portion was identified by temporary ligation of the renal interlobar branch (Fig. 2A) and, finally, a 15/16 subtotal Nx was performed by selectively ligating branches of the renal artery.

\section{Clinical observations}

Ten male Beagles were included in group A. All dogs were treated with amlodipine for 2 weeks after the second surgery to prevent excessively high BP. Although some dogs exhibited 
A

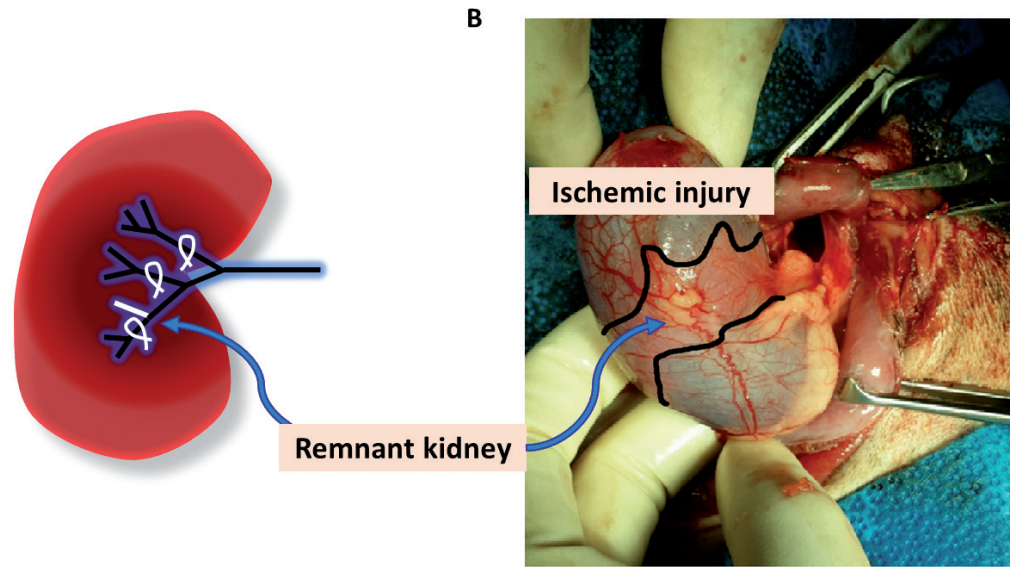

B
Figure 2. A. Identified regions of remnant kidney and ischemic injury by ligation of renal arteries in Beagle dogs. B. Schematic drawing of renal arterial branches of the Beagle dog kidney. White circles indicate the points of renal arterial ligation for $15 / 16$ nephrectomy $(\mathrm{Nx})$ in this study. mild clinical signs associated with renal disease and hypertension, no dog in this group died or required uthanasia.

Eleven male Beagles were included in group B; however, 3 dogs were excluded from the study. Two of these dogs developed azotemia (BUN $190.2 \mathrm{mg} / \mathrm{dl}$, sCr $11.5 \mathrm{mg} / \mathrm{dl}$, and $\mathrm{uP} / \mathrm{C} 2.22$; BUN $188.0 \mathrm{mg} / \mathrm{dl}, \mathrm{sCr} 7.43 \mathrm{mg} / \mathrm{dl}$, and $\mathrm{uP} / \mathrm{C} 4.73$ ), and marked hypertension (SBP $198 \mathrm{mmHg}$; SBP $209 \mathrm{mmHg}$ ) at 2 weeks after the second surgery and died on postoperative day 16 . The remaining dog developed severe hypertension (SBP $243 \mathrm{mmHg}$, BUN/ sCr 150.7/5.68, and $\mathrm{UP} / \mathrm{C} 2.69$ ) and died 10 days after the second surgery with severe clinical signs of lethargy, anorexia, bloody feces, stomatitis, convulsion, and vomiting. As a result, 8 Beagle dogs were enrolled in the study. The remaining animals were treated with amlodipine to improve their clinical signs and to prevent death from marked hypertension and
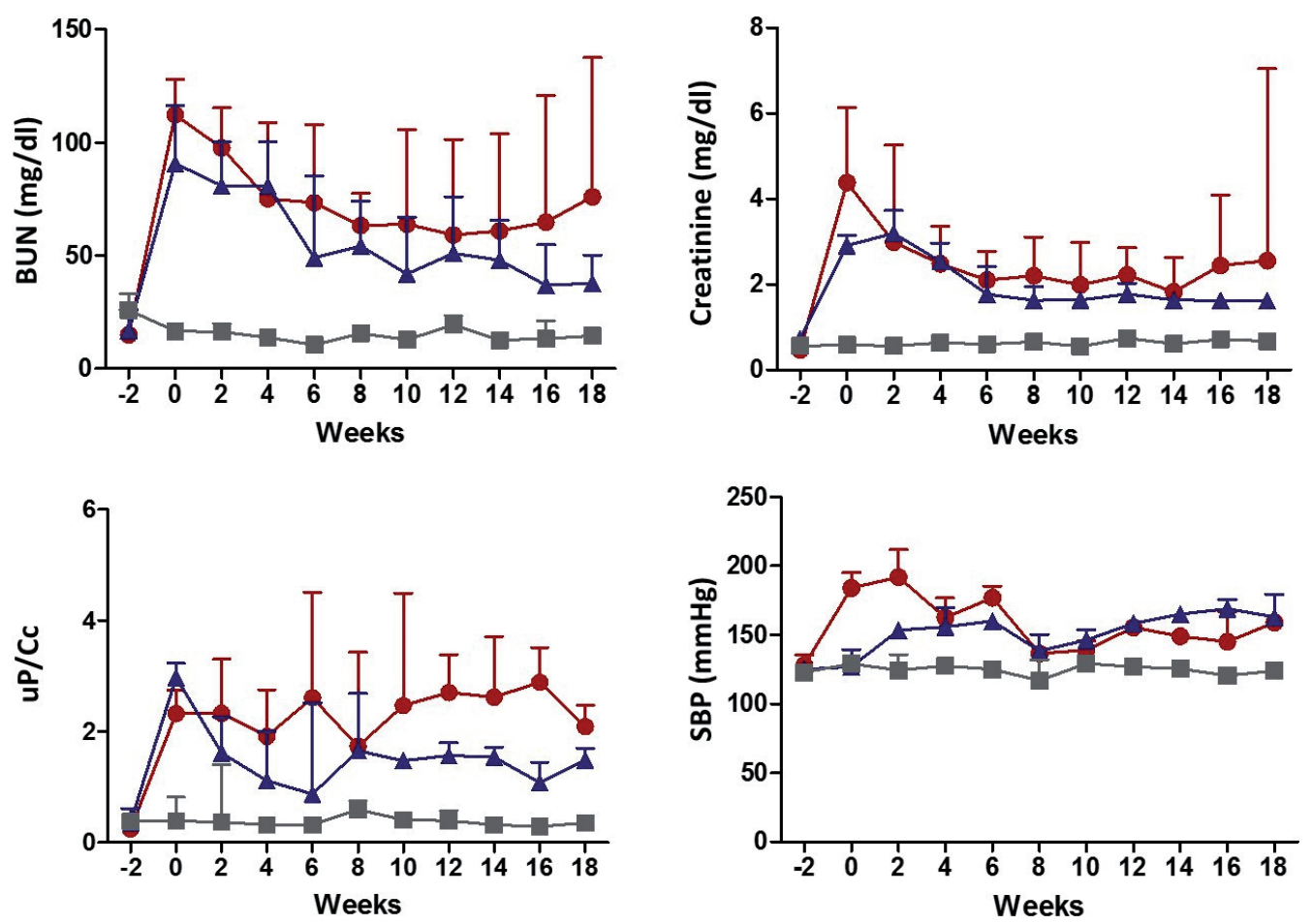

Sham group $\triangle$ Group $A$

Group B

Figure 3. The course of renal function and systolic blood pressure over 20 weeks in sham group, group A, and group B. BUN, blood urea nitrogen; SBP, systolic blood pressure; $\mathrm{uP} / \mathrm{C}$, urine protein/creatinine ratio. 
severe kidney disease, except in the 2 weeks immediately after surgery. These dogs completed the observation period without developing severe abnormalities.

The four sham-operated dogs exhibited no clinical signs associated with renal disease and hypertension.

\section{$S B P$}

SBP in the group A dogs with CKD was controlled to $<160 \mathrm{mmHg}$ until 2 weeks after renal ligation, but gradually increased, and all dogs exhibited high BP at the conclusion of the study (Fig. 3). In contrast, SBP was highest in the group $\mathrm{B}$ dogs with CKD during the first 2 weeks without any antihypertensive medication. Thereafter, whenever a dog was identified with SBP $>180 \mathrm{mmHg}$ or a clinical abnormality, amlodipine was administered. SBP decreased dramatically in all dogs in group B. The mean SBP in group A (147.5 \pm $2.3 \mathrm{mmHg})$ was higher than in group $\mathrm{B}(139.0 \pm 3.6 \mathrm{mmHg})$ at 10 weeks after surgery $(p=0.054)$; however, there was no statistically significant difference between the two groups at 18 weeks $(p=0.145)$. The SBP in the sham-operated dogs was in the normal range in both groups during the study.

\section{Renal function analysis}

The main difference between group A and group B dogs was the administration of a hypertensive agent during the first 2 weeks after surgery. Although the estimated values for BUN, $\mathrm{sCr}$, and $\mathrm{uP} / \mathrm{C}$ in group A were significantly elevated after surgery, they were lower than in group B overall ( $p=0.014$, $p=0.020$, and $p=0.007$, respectively). In contrast, there was no elevation in $\mathrm{BUN}, \mathrm{sCr}$, or $\mathrm{uP} / \mathrm{C}$ in the sham-operated dogs. The renal function in all dogs is presented in Figure 3.

In group $\mathrm{A}$, the mean $\mathrm{BUN}$ level was $>75 \mathrm{mg} / \mathrm{dl}$ during the first 2 weeks and slowly decreased thereafter until the final week of the study. No dog had a BUN $>100 \mathrm{mg} / \mathrm{dl}$ at 3 weeks. At 16 weeks, the mean BUN was lowest (41.64 \pm $16.51 \mathrm{mg} / \mathrm{dl}$ ) in group A and was within the normal range $(<25 \mathrm{mg} / \mathrm{dl})$ in 2 of the 10 dogs. The highest mean $\mathrm{sCr}$ in group A was at 2 weeks $(3.41 \pm 0.99 \mathrm{mg} / \mathrm{dl})$, unlike in group B. After 3 weeks, the mean $\mathrm{sCr}$ steadily decreased until the final week. The $\mathrm{sCr}$ was lowest $(1.54 \pm 0.38 \mathrm{mg} / \mathrm{dl})$ in the final week and within the normal range $(<1.5 \mathrm{mg} / \mathrm{dl})$ in 6 of 10 dogs. The mean $\mathrm{uP} / \mathrm{C}$ values in the dogs were $>1.0$ for the entire duration of the experimental period after the second surgery. The highest and lowest mean $\mathrm{uP} / \mathrm{C}$ values in the dogs were at 1 week $(2.87 \pm 0.51)$ and 18 weeks (1.09 $\pm 0.45)$, respectively.

In group $\mathrm{B}$, the baseline $\mathrm{BUN}, \mathrm{sCr}$, and $\mathrm{uP} / \mathrm{C}$ values were significantly increased after the second surgery. The mean BUN was $>90 \mathrm{mg} / \mathrm{dl}$ during the first 3 weeks in this group. Moreover, 5 of 8 surviving dogs had a BUN $>100 \mathrm{mg} / \mathrm{dl}$ at 2 weeks. Thereafter, it slowly decreased until 15 weeks. At this time, the BUN was lowest $(57.21 \pm 38.51 \mathrm{mg} / \mathrm{dl})$ and within the normal range $(<25 \mathrm{mg} / \mathrm{dl})$ in 3 of 8 dogs with CKD. After 15 weeks, the BUN concentration increased again to $>70 \mathrm{mg} /$ $\mathrm{dl}$. The mean $\mathrm{sCr}$ value was $4.17 \pm 1.95 \mathrm{mg} / \mathrm{dl}$ after surgery and steadily decreased until 15 weeks. At this time, the $\mathrm{sCr}$ was lowest $(1.98 \pm 0.87 \mathrm{mg} / \mathrm{dl})$ and within the normal range $(<1.5 \mathrm{mg} / \mathrm{dl})$ in 3 of 8 dogs. After 16 weeks, the mean $\mathrm{sCr}$ value increased again to levels $>2 \mathrm{mg} / \mathrm{dl}$. The mean $\mathrm{uP} / \mathrm{C}$ in dogs was $>1.5$ for the entire experimental period after the second surgery. The lowest mean $\mathrm{uP} / \mathrm{C}$ in the dogs was at 2 weeks $(1.66 \pm 0.68)$ and $16(1.66 \pm 0.80)$ weeks, and the highest value was at 12 weeks $(3.19 \pm 1.96)$.

The mean $\mathrm{BUN}$ and $\mathrm{sCr}$ in four sham-operated dogs were $14.54 \pm 4.09 \mathrm{mg} / \mathrm{dl}$ and $0.64 \pm 0.07 \mathrm{mg} / \mathrm{dl}$, respectively. One sham-operated dog had an abnormal uP/C value (1.73) at 2-4 weeks; thereafter its $\mathrm{uP} / \mathrm{C}$ value decreased until it reached 0.26 . There were no abnormal $\mathrm{uP} / \mathrm{C}$ values in the other dogs.

\section{Kidney tissue}

Tissue samples were obtained after the end of the 18-week study. Dogs with CKD in group B exhibited more significant histological damage, as assessed by increased tubular interstitial fibrosis, tubular atrophy, and inflammation than dogs in group A, whereas the sham group exhibited normal kidney structure. Development of kidney fibrosis was confirmed by periodic acid-Schiff, Masson's trichrome, and Sirius red staining (Fig. 4A), and correlated with increased collagen IV and aSMA levels (Fig. 4C). Group B exhibited more glomerular sclerosis $(p=0.015)$ and a higher semiquantitative score for fibrotic area $(p=0.007)$ than group A when evaluated according to Masson's trichrome staining (Fig. 4B). Kidney inflammation was demonstrated by NF- $\kappa B / p 65$ and macrophage (Fig. 4D). Phosphorylated extracellular signal-regulated protein kinase played a role in apoptosis of tubular epithelial cells and increased in dogs with CKD in group B (Fig. 5) (Pat et al. 2005).

\section{Discussion}

In this study, we established a sophisticated canine model of CKD by 15/16 Nx. We also demonstrated that successful management of $\mathrm{BP}$ in the early stages of $\mathrm{CKD}$ is an important factor in slowing the progression of fibrosis.

A reduction of renal mass, which means a decrease in the nephron/glomerular number, reduces kidney function and results in hyperfiltration of the remaining kidney, which leads to progression to kidney damage (Shirasaki et al. 2004). Similar consequences have occurred in human subjects with nephrectomy due to donation and renal cell carcinoma (Chapman et al. 2010; Kim et al. 2012; Li et al. 2014). The 
reduction of renal mass has been used as a CKD induction model in animals. Over recent decades, $1 / 2$ to $15 / 16 \mathrm{Nx}$ procedures have been used when the canine remnant kidney model has been used to study CKD (Brown 2013). Although $5 / 6 \mathrm{Nx}$ in mice has been sufficient to induce CKD, 1/2 to
7/8 Nx in dogs has not been accompanied by progressive renal damage (Bourgoignie et al. 1987; Santos et al. 2006). This supports the view that canine kidneys are more resistant to systemic hypertension than rodent kidneys, and an Nx of at least $15 / 16$ is necessary to create a canine remnant

A
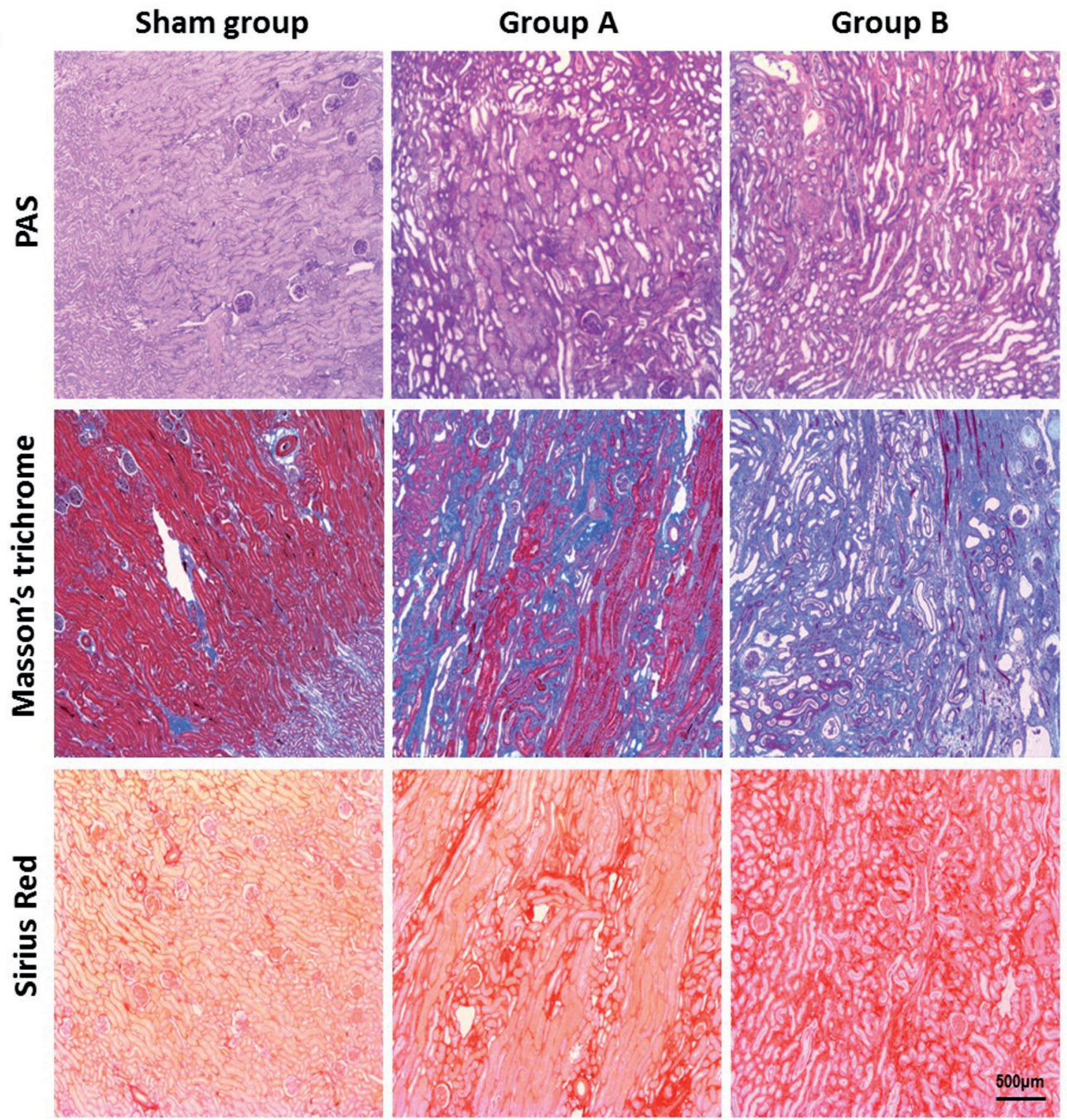

B
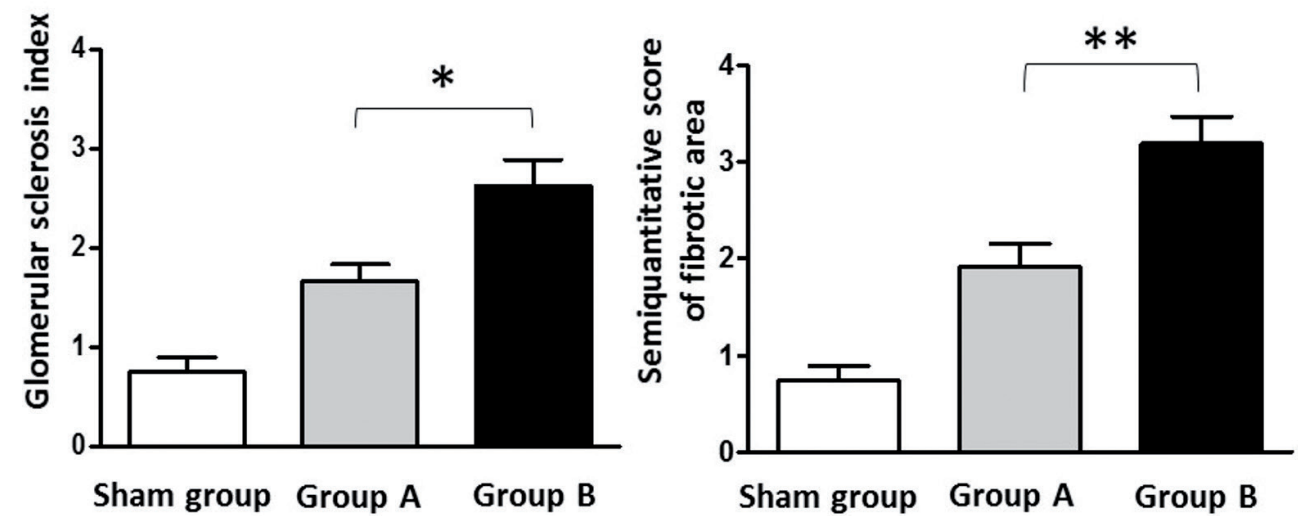


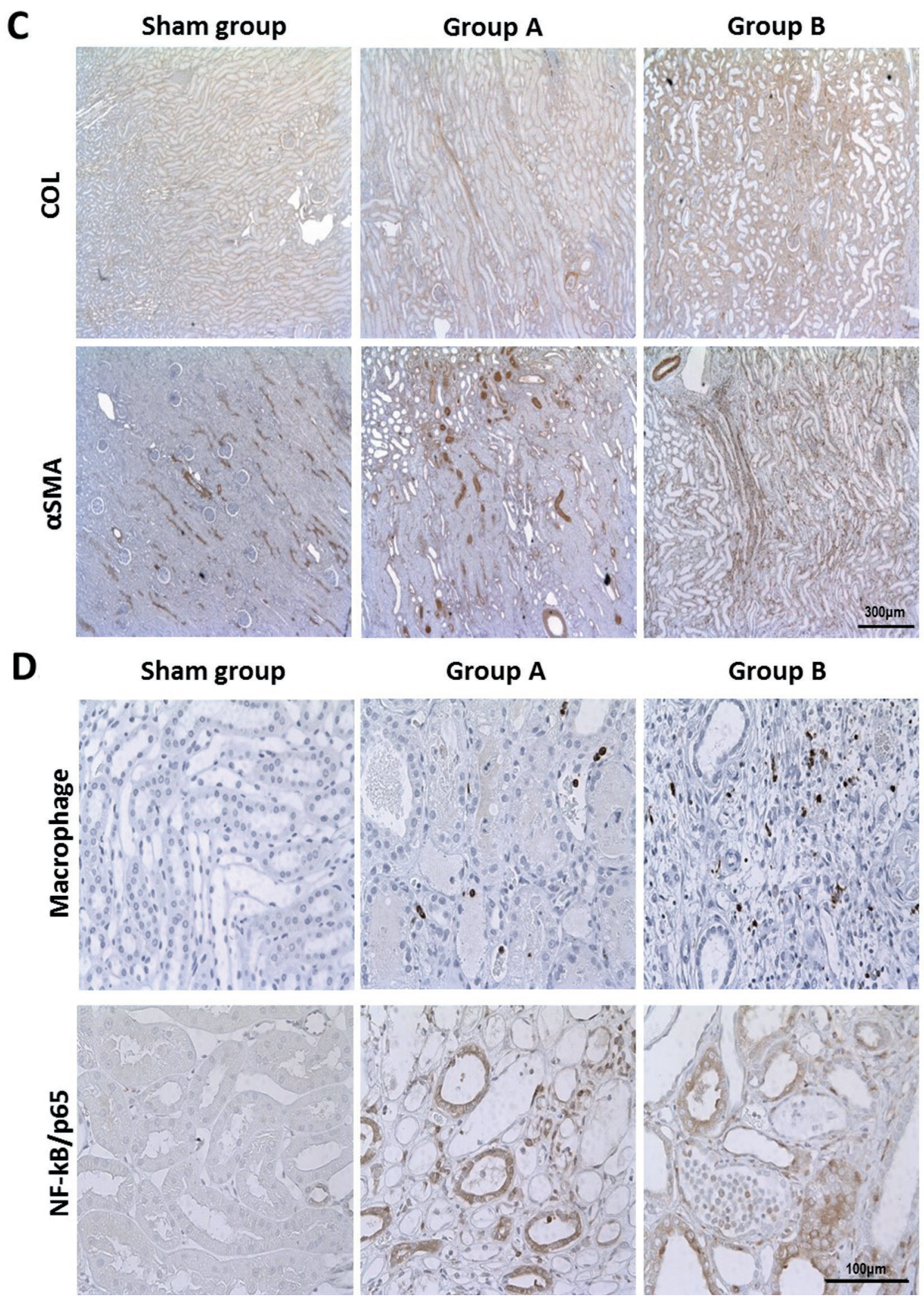

4Figure 4. Morphological profiles of the kidney cortex from dogs with chronic kidney disease (CKD) according to timing of blood pressure control. A. Dogs with CKD exhibited significantly more tubular atrophy, mononuclear inflammatory infiltration, and fibrosis than the dogs in the sham group. Group B exhibited more aggressive fibrosis than group A, as indicated by periodic acid-Schiff, Masson's trichrome, and Sirius Red staining. (400× objective). B. Fibrosis as assessed by Masson's trichrome in all groups of Beagle dogs. ${ }^{\star} p<0.05 ;{ }^{* *} p<0.001$. C. Immunochemical staining results for type IV collagen and aSMA in kidney tissues. Kidney injury and renal interstitial fibrosis were detected more often in dogs with CKD, especially in group B, than in the sham group (100× objective). D. Immunohistochemical staining of fibrotic markers: p65, macrophage were performed to detect the degree of tubulointerstitial fibrosis in CKD group, especially in group B (400× objective). 
kidney model for use in a CKD study. Therefore, among the available experimental models for canine CKD, 15/16 Nx has been mainly used (Brown et al. 1991; Finco 2004). We successfully established the 1/16 remnant kidney model in Beagle dogs for induction of CKD and achieved marked impairment of renal function in both CKD groups. A previous study reported that dietary phosphorus restriction improved the survival rate following $15 / 16 \mathrm{Nx}$ in mongrel dogs without drug treatment (Brown et al. 1991). However, unlike that study, the present study did not include a change in dietary formula, even though the dogs with CKD were in an abnormal state (i.e., post-Nx and with uremia). Instead of altering diet, CKD was controlled in these dogs by the use of hypertensive drugs to mitigate the effect of dietary change(s). Consequently, the survival rate in our Beagle dogs with CKD was similar to that of mongrel dogs with CKD in a previous study (Brown et al. 1991). Although previous studies and our own study used different species of dogs, the results suggest that a hypertensive drug and dietary mineral restriction can improve survival in dogs with CKD.

Non-human primates have been regarded as ideal experimental animals because of their structural and functional similarities to humans. However, monkeys and chimpanzees have the same emotions as humans and share common infections. In addition, they are expensive and difficult to handle.
For these reasons, experimentation involving non-human primates is prohibited in many countries (Coors et al. 2010). Dogs have been used in the development of nephrologic care, especially in dialysis and transplantation (Abel et al. 1914; Yarger and Griffith 1974; Tilney 2003). Blood vessels and kidney mass of dogs are so large that it is easier to operate compared with rats or mice. The canine model of CKD is similar to that of human CKD, and helps our physiological and pathophysiological understanding of the disease in humans as well as in dogs. Therefore, development of a sophisticated canine CKD model is important for conducting experiments and understanding CKD in humans.

The International Renal Interest Society criterion for diagnosis of hypertension in dogs has been proposed for clinical canine patients (Grauer 2017). However, it is known that estimation of BP in untrained or non-anesthetized dogs is more erratic and higher than in trained or anesthetized dogs (Bartges et al. 1996). Therefore, an SBP >180 mmHg in untrained dogs has been suggested to indicate hypertension and was treated with antihypertensive drugs in our study.

Three dogs in group B developed severe clinical signs, including anorexia, mild lethargy, vomiting, and rapid loss of body weight, in the 2 weeks following the second surgery. After the onset of clinical signs, their physical state deteriorated rapidly and they were humanely euthanized.
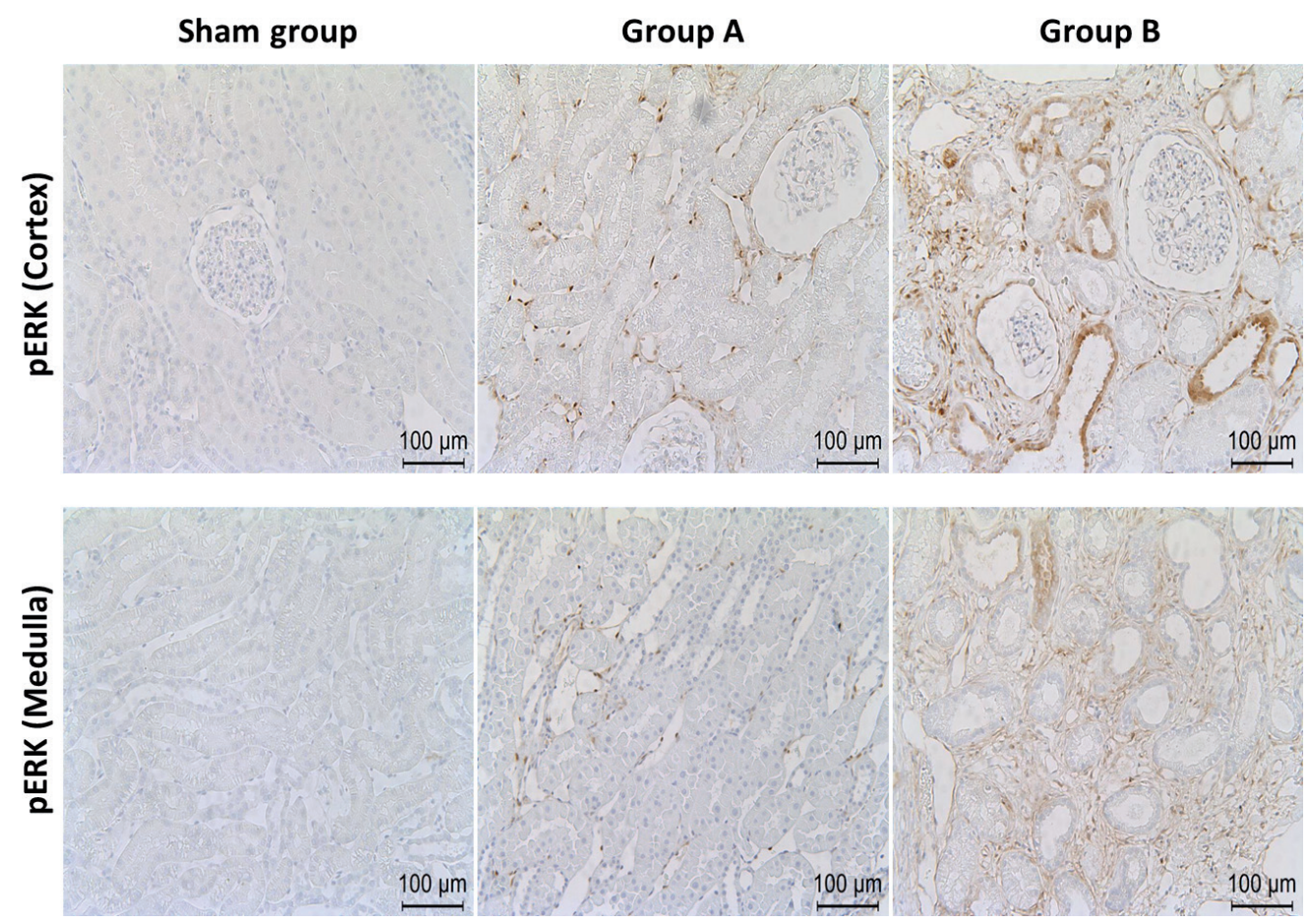

Figure 5. Immunolocalization of phosphorylated extracellular signal-regulated protein kinase (pERK) in a chronic kidney disease (CKD) model, in which pERK was found in the tubular epithelium in the outer medulla, with many dual-labeled epithelial cells (200× objective). 
However, although the other dogs that had hypertension (SBP $>180 \mathrm{mmHg}$ ) did not exhibit significant clinical signs, amlodipine was administered to prevent sudden death.

In our study, both groups of CKD models exhibited higher creatinine, higher proteinuria, and higher BP than the sham groups. Most of the values had stabilized by 4 weeks postoperatively. The main difference between group A and group B was the management of BP during the first 2 weeks after surgery. In group A dogs, SBP was controlled to $<160 \mathrm{mmHg}$ until 16 weeks and $<180 \mathrm{mmHg}$ until 18 weeks. Interestingly, renal function in group A was better than in group B throughout the study. Furthermore, less severe inflammation and fibrosis were observed in kidney tissue samples from group A than in group B. A study investigating the renal consequences of $\mathrm{Nx}$ found that the remaining kidney adapts functionally by renal hyperfiltration (Tilney 2003). However, renal hyperfiltration impacts kidney function and leads progressively to CKD (Hostetter et al. 1981, 1995; Finn 1982). The remnant kidney may be at its most vulnerable immediately after the surgical procedure. Changes in the hemodynamics of the kidney that result in renal hyperfiltration are a crucial factor in the progression of CKD (Mueller and Luyckx 2012). This observation supports that view that early management is important to control risk factors that may cause kidney injury. Strict BP control in the early stage of CKD may suppress the progression of iatrogenic $\mathrm{CKD}$, such as $\mathrm{Nx}$, in a patient with renal cell carcinoma or a kidney donation for transplantation. Although we did not observe progression of tubular fibrosis or glomerular changes on histopathological examination midway through the study, early glomerular injury and subsequent onset of tubular fibrosis would be expected based on the trend in $\mathrm{uP} / \mathrm{C}$ and later histological findings.

In summary, we established a sophisticated model of CKD using 15/16 Nx in Beagle dogs, which may help us better understand CKD in humans. Control of BP as soon as possible will help prevent progression of the disease. In this canine model of stable CKD, we established that early BP control has a favorable effect in patients with CKD.

Acknowledgements. This work was supported by the Korean Healthcare Technology R\&D Project of Ministry for Health and Welfare, Republic of Korea (Grant HI14C0559).

Conflict of interest. The authors have no conflicts of interest to declare.

\section{References}

Abel JJ, Rowntree LG, Turner BB (1914): On the removal of diffusible substances from the circulating blood of living animals by dialysis. J. Pharmacol. Exp. Ther. 5, 275-316

Acierno MJ, Labato MA (2004): Hypertension in dogs and cats. Compendium 26, 4
Adams LG., Polzin DJ, Osborne CA, O'Brien TD (1992): Correlation of urine protein/creatinine ratio and twenty-four-hour urinary protein excretion in normal cats and cats with surgically induced chronic renal failure. J. Vet. Intern. Med. 6, 36-40 https://doi.org/10.1111/j.1939-1676.1992.tb00983.x

Al Banchaabouchi M, Marescau B, D'Hooge R, Van Marck E, Van Daele A, Levillain O, De Deyn PP (1998): Biochemical and histopathological changes in nephrectomized mice. Metabolism 47, 355-361 https://doi.org/10.1016/S0026-0495(98)90271-2

Bartges JW, Willis AM, Polzin DJ (1996): Hypertension and renal disease. Vet. Clin. North Am. Small Anim. Pract. 26, 1331-1345 https://doi.org/10.1016/S0195-5616(96)50131-2

Bourgoignie JJ, Gavellas G, Martinez E, Pardo V (1987): Glomerular function and morphology after renal mass reduction in dogs. J. Lab. Clin. Med. 109, 380-388

Bovee K, Kronfeld D, Ramberg C, Goldschmidt M (1979): Longterm measurement of renal function in partially nephrectomized dogs fed 56, 27, or 19\% protein. Invest. Urol. 16, 378-384

Brown SA (2013) Renal pathophysiology: lessons learned from the canine remnant kidney model. J. Vet. Emerg. Crit. Care (San Antonio) 23, 115-121

https://doi.org/10.1111/vec.12030

Brown SA, Crowell WA, Barsanti JA, White J, Finco D (1991): Beneficial effects of dietary mineral restriction in dogs with marked reduction of functional renal mass. J. Am. Soc. Nephrol. 1, 1169-1179

Coors ME, Glover JJ, Juengst ET, Sikela JM (2010): The ethics of using transgenic non-human primates to study what makes us human. Nat. Rev. Genet. 11, 658-662 https://doi.org/10.1038/nrg2864

Chapman D, Moore R, Klarenbach S, Braam B (2010): Residual renal function after partial or radical nephrectomy for renal cell carcinoma. Can. Urol. Assoc. 4, 337-343 https://doi.org/10.5489/cuaj.909

Coulter D, Keith J, Jr. (1984): Blood pressures obtained by indirect measurement in conscious dogs. J. Am. Vet. Med. Assoc. 184, $1375-1378$

Dong Y, Wang W, Cao J, Fan P, Lin X (2013): Quantitative evaluation of contrast-enhanced ultrasonography in the diagnosis of chronic ischemic renal disease in a dog model. PLoS One 8, e70337 https://doi.org/10.1371/journal.pone.0070337

Finco DR (2004): Association of systemic hypertension with renal injury in dogs with induced renal failure. J. Vet. Intern. Med. 8, 289-294 https://doi.org/10.1111/j.1939-1676.2004.tb02547.x

Finn W (1982): Compensatory renal hypertrophy in SpragueDawley rats. Kidney Blood Press Res. 5, 222-234 https://doi.org/10.1159/000172861

Gava AL, Freitas FP, Balarini CM, Vasquez EC, Meyrelles SS (2012): Effects of 5/6 nephrectomy on renal function and blood pressure in mice. Int. J. Physiol. Pathophysiol. Pharmacol. 4, 167-173

Grauer GF (2017): Treatment Guidelines for Chronic Kidney Disease in Dogs and Cats. IRIS 7

Griffin KA, Picken M, Bidani AK (1994): Method of renal mass reduction is a critical modulator of subsequent hypertension and glomerular injury. J. Am. Soc. Nephrol. 4, 2023-2031 
Haas CS, Amann K, Schittny J, Blaser B, Müller U, Hartner A (2003): Glomerular and renal vascular structural changes in $a 8$ integrin-deficient mice. J. Am. Soc. Nephrol. 14, $2288-2296$ https://doi.org/10.1097/01.ASN.0000082999.46030.FE

Hostetter T, Olson J, Rennke H, Venkatachalam M, Brenner B (1981): Hyperfiltration in remnant nephrons: a potentially adverse response to renal ablation. Am. J. Physiol. Renal Physiol. 241, F85-F93 https://doi.org/10.1152/ajprenal.1981.241.1.F85

Hostetter TH (1995): Progression of renal disease and renal hypertrophy. Annu. Rev. Physiol. 57, 263-278 https://doi.org/10.1146/annurev.ph.57.030195.001403

Ibrahim H, Hostetter T (1998): The renin-aldosterone axis in two models of reduced renal mass in the rat. J. Am. Soc. Nephrol. 9, 72-76

Jacob F, Polzin DJ, Osborne CA, Neaton JD, Lekcharoensuk C, Allen TA, Kirk CA, Swanson LL (2003): Association between initial systolic blood pressure and risk of developing a uremic crisis or of dying in dogs with chronic renal failure. J. Am. Vet. Med. Assoc. 222, 322-329 https://doi.org/10.2460/javma.2003.222.322

Kim S, Hwang H, Yoon H, Kim Y, Choi B, Moon I, Kim J, Hwang T, Kim Y, Yang C (2012): Long-term risk of hypertension and chronic kidney disease in living kidney donors. Transplant. Proc. 44, 632-634 https://doi.org/10.1016/j.transproceed.2011.12.066

Kren S, Hostetter TH (1990): The course of the remnant kidney model in mice. Kidney Int. 56, 333-337 https://doi.org/10.1046/j.1523-1755.1999.00527.x

Kujal P, Vernerova Z (2008): 5/6 Nephrectomy as an experimental model of chronic renal failure and adaptation to reduced nephron number. Cesk. Fysiol. 57, 104-109 (in Czech)

Li L, Lau WL, Rhee CM, Harley K, Kovesdy CP, Sim JJ, Jacobsen S, Chang A, Landman J, Kalantar-Zadeh K (2014): Risk of chronic kidney disease after cancer nephrectomy. Nat. Rev. Nephrol. 5, 135-145 https://doi.org/10.1038/nrneph.2013.273

Madias NE (1983): Hemodynamically mediated glomerular injury and the progressive nature of kidney disease. Kidney Int. 23, 647-655 https://doi.org/10.1038/ki.1983.72

Marques-Sampaio BP, Pereira-Sampaio MA, Henry RW, Favorito LA, Sampaio FJ (2007): Dog kidney: anatomical relationships between intrarenal arteries and kidney collecting system. Anat. Rec. 290, 1017-1022

https://doi.org/10.1002/ar.20567

Monroe WE., Davenport D, Saunders GK (1989): Twenty-four hour urinary protein loss in healthy cats and the urinary protein-creatinine ratio as an estimate. Am. J.Vet. Res. 50, 1906-1909

Mueller TF, Luyckx VA (2012): The natural history of residual renal function in transplant donors. J. Am. Soc. Nephrol. 23, 1462-1466

https://doi.org/10.1681/ASN.2011111080
Pat B, Yang T, Kong C, Watters D, Johnson DW, Gobe G (2005): Activation of ERK in renal fibrosis after unilateral ureteral obstruction: modulation by antioxidants. Kidney Int. 67, 931-943 https://doi.org/10.1111/j.1523-1755.2005.00157.x

Peterson JC, Adler S, Burkart JM, Greene T, Hebert LA, Hunsicker LG, King AJ, Klahr S, Massry SG, Seifter JL (1995): Blood pressure control, proteinuria, and the progression of renal disease. The modification of diet in renal disease study. Ann. Intern. Med. 123, 754-762 https://doi.org/10.7326/0003-4819-123-10-199511150-00003

Polzin D, Leininger J, Osborne C, Jeraj K (1988): Development of renal lesions in dogs after 11/12 reduction of renal mass. Influences of dietary protein intake. Lab. Invest. 58, 172-183

Purkerson ML, Hoffsten PE, Klahr S (1976): Pathogenesis of the glomerulopathy associated with renal infarction in rats. Kidney Int. 9, 407-417 https://doi.org/10.1038/ki.1976.50

Ravera M, Re M, Deferrari L, Vettoretti S, Deferrari G (2006): Importance of blood pressure control in chronic kidney disease. J. Am. Soc. Nephrol. 17 (Suppl 2), S98-S103 https://doi.org/10.1681/ASN.2005121319

Robertson JL, Goldschmidt M, Kronfeld DS, Tomaszewski JE, Hill GS, Bovee KC (1986): Long-term renal responses to high dietary protein in dogs with $75 \%$ nephrectomy. Kidney Int. 29, 511-519 https://doi.org/10.1038/ki.1986.29

Santos LS, Chin EWK, Ioshii SO, Tambara Filho R (2006): Surgical reduction of the renal mass in rats: morphologic and functional analysis on the remnant kidney. Acta Cir. Bras. 21, 252-257 https://doi.org/10.1590/S0102-86502006000400012

Sarnak MJ, Greene T, Wang X, Beck G, Kusek JW, Collins AJ, Levey AS (2005): The effect of a lower target blood pressure on the progression of kidney disease: long-term follow-up of the Modification of diet in renal disease study. Ann. Intern. Med. 142, 342-351 https://doi.org/10.7326/0003-4819-142-5-200503010-00009

Shirasaki Y, Tsushima T, Saika T, Nasu Y, Kumon H (2004): Kidney function after nephrectomy for renal cell carcinoma. Urology 64, 43-47 https://doi.org/10.1016/j.urology.2004.02.039

Tilney NL (2003): Transplant: From Myth to Reality. New Haven, CT: Yale University Press

Upadhyay A, Earley A, Haynes SM, Uhlig K (2011): Systematic review: blood pressure target in chronic kidney disease and proteinuria as an effect modifier. Ann. Intern. Med. 154, 541-548

https://doi.org/10.7326/0003-4819-154-8-201104190-00335

Yarger W, Griffith L (1974): Intrarenal hemodynamics following chronic unilateral ureteral obstruction in the dog. Am. J. Physiol. 227, 816-826 https://doi.org/10.1152/ajplegacy.1974.227.4.816

Received: September 11, 2017

Final version accepted: November 7, 2017

First published online: March 28, 2018 